\title{
OPTIMIZING PROCESS PARAMETERS FOR IONIC LIQUID CATALYZED Tert-BUTYLATION OF PHENOL USING RESPONSE SURFACE METHODOLOGY
}

\author{
P. Elavarasan ${ }^{1, \bigotimes}$, S. Rengadurai ${ }^{1}$, S. B. Riswan Ali ${ }^{1}$, S. Ramesh ${ }^{1}$, \\ N. Varagunapandiyan ${ }^{2}$, M. R. Ezhilarasi ${ }^{3}$ and Sreedevi Upadhyayula ${ }^{4}$ \\ ${ }^{1}$ Department of Chemical Engineering, Annamalai University, Annamalai nagar, Tamil nadu, India. \\ ${ }^{2}$ Department of Chemical Engineering, King Khalid University, Abha-61421, Saudi Arabia \\ ${ }^{3}$ Department of Chemistry, Karpagam Academy of Higher Education, Coimbatore, \\ Tamil Nadu, India. \\ ${ }^{4}$ Department of Chemical Engineering, Indian Institute of Technology Delhi, New Delhi, India \\ ${ }^{\bowtie}$ Corresponding Author: pe08135@annamalaiuniversity.ac.in
}

\begin{abstract}
Tert-butylation of phenol using N-(1,4-sulfonic acid) butyl triethylammonium hydrogen sulfate ionic liquid catalyst in a batch reactor is optimized the process parameters using Response Surface Methodology. A BoxBehnken experimental design is applied to optimize the parameters such as Reaction time, temperature, reactant mole ratio and catalyst (IL) to phenol mole ratio of reaction. The optimized parameters are to minimize stringent experimental conditions and maintain the usage of catalyst. Maximum phenol conversion and selective yield of 2,4-DTBP were found in batch experiments at modest temperature, phenol to alcohol ratio, catalyst (IL) to phenol ratio with optimum time.
\end{abstract}

Keywords: tert-butylation, Ionic Liquid, Phenol, Box-Behnken, 2,4-DTBP.

RASĀYAN J. Chem., Vol. 14, No.1, 2021

\section{INTRODUCTION}

Alkylations are industrially important reactions and the alkylated products find a wide variety of applications. Butylated phenol is one such industrially important product and finds application as raw material and intermediate in the manufacture of many chemical compounds like antioxidants and UVstabilizers. ${ }^{1-3}$ These important, acid-catalyzed alkylation technologies need to be upgraded continuously with environmentally friendly and economic catalyst systems. More than 15 billion pounds per year of alkyl aromatics use liquid acid catalysts. Homogeneous and heterogeneous catalysts are widely used for butylated phenol production reported by previous researchers. ${ }^{4-10}$ Nevertheless, acids catalysts have the demerits such as reactant conversion, product selectivity, spent catalyst disposal, catalyst recoverability and ecofriendly process. In past decades, Ionic Liquids (ILs) have originated as an environmentally benign alternate replacement for the reaction media. ${ }^{11-15}$ Naturally ILs have physical and chemical properties such as thermal stability, negligible vapor pressure, recoverability, separation of products from reactants are simple and chemically stable liquids even at room temperature. Before scaled-up, the reaction both in batch and continuous reactor, the process variables such as reactant conversion and selective yield of product need to be optimized in the laboratory to the maximum with economically viable. Statistical parameter optimization technique tools are used to minimize number reaction with rigorous experimental Conditions. Therefore, the present study was aimed to establish the optimum conditions such as time, temperature, reactant mole ratio and catalyst loading to achieve maximum phenol conversion and selective yield of product using the response surface methodology (RSM). Tert-butylation of phenol with tert-butyl alcohol as an alkylation agent in sulfonic acid functionalized (Bronsted acid) ionic liquid catalyst has been investigated using RSM.

\section{Material and Methods}

\section{EXPERIMENTAL}

Materials and reagents: The experiments were conducted using commercially available solvents and chemicals and are used without further purification. Triethylamine and 1, 4-butane sultone are supplied by M/s Sigma Aldrich Chemicals Pvt. Ltd., India. Phenol, tert-butyl alcohol and sulfuric acid are supplied by M/s Merck \& CDH., New Delhi, India.

Rasayan J. Chem., 14(1), 261-269(2021)

http://dx.doi.org/10.31788/ RJC.2021.1416120

This work is licensed under a CC BY 4.0 license. 
Synthesis of ionic liquid: In a typical ionic liquid (N-(1,4-sulfonic acid) butyl triethylammonium hydrogen sulfate) preparation procedure, ${ }^{16-18}$ triethylamine (0.1 moles) was mixed with 1,4-butanesultone $(0.1 \mathrm{~mol})$ stirring for about 12 hours at $80^{\circ} \mathrm{C}$. After solidification, the zwitterion mass was washed with ethyl ether and then dried under a vacuum. A stoichiometric amount of sulfuric acid $(0.1$ mol) was then added to the precursor zwitterion. The mixture was stirred at $80^{\circ} \mathrm{C}$ for 8 hours to obtain the ionic liquid. Further, Ionic liquids washed with di-ethyl ether and toluene, dried under vacuum. Scheme 1 shows the structure of the prepared ionic liquid. 1H-NMR (D2O, $400 \mathrm{MHz}): \delta(\mathrm{ppm}) 1.16$ $(\mathrm{t}, 9 \mathrm{H}), 1.66(\mathrm{~m}, 4 \mathrm{H}), 2.59(\mathrm{t}, 2 \mathrm{H}), 3.14(\mathrm{t}, 2 \mathrm{H}), 3.2(\mathrm{~m}, 6 \mathrm{H}) ; 13 \mathrm{C}-\mathrm{NMR}(\mathrm{D} 2 \mathrm{O}, 100 \mathrm{MHz}): \delta(\mathrm{ppm})$ $8.00,20.69,22.77,51.05,23.87,56.65$. The thermal decomposition of the ionic liquid is $325^{\circ} \mathrm{C}$.

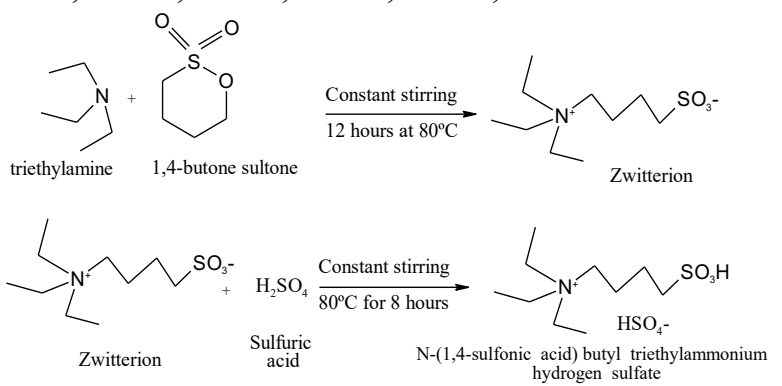

Scheme-1: Synthesis of Ionic Liquid

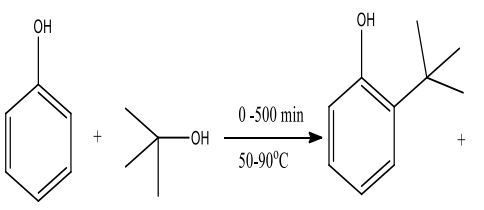

Phenol

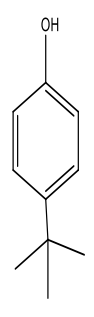

4-ТВР

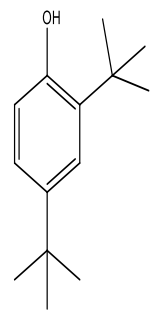

2,4-DTBP

Scheme-2: IL Catalyzed Alkylation Reaction Mechanism

\section{Batch Alkylation}

The alkylation was carried out under autogeneous pressure, in a sealed glass tube batch reactor, equipped with a magnetic stirrer. In a typical batch reaction, $10 \mathrm{mmol}$ each of phenol, TBA and ionic liquids (mole ration 1:1:1). The initial reaction temperature was maintained at $70^{\circ} \mathrm{C}$ and the reaction mixture was stirred at $600 \mathrm{rpm}$ for 480 minutes. At the end of the reaction, the mixture was cooled and the products were extracted by toluene. Quantitative analysis was conducted with a NUCON GC supplied by AIMIL India Ltd. in a CHROMSORB-WHP ( $2 \mathrm{~m} \times 3.175 \mathrm{~mm} \times 2 \mathrm{~mm})$ column using a FID. The range of these process parameters chosen for an optimization was, temperature $50^{\circ} \mathrm{C}$ to $90^{\circ} \mathrm{C}$, time 20 to $480 \mathrm{~min}$, IL to phenol mole ratio 0.5 to 2 and reactant mole ratio 1 to 3 .

Table-1: Parameter Levels and Coded Values used in the Experimental Design

\begin{tabular}{c|c|c|c|c}
\hline Factors & Symbol & \multicolumn{3}{|c}{ Range and Level } \\
\hline & & -1 & 0 & +1 \\
\hline Time (min.) & $x_{1}$ & 20 & 250 & 480 \\
\hline Temperature $\left({ }^{\circ} \mathrm{C}\right)$ & $x_{2}$ & 50 & 70 & 90 \\
\hline Phenol to tert-butanol mole ratio & $x_{3}$ & 1 & 2 & 3 \\
\hline Catalyst (IL) to phenol mole ratio & $x_{4}$ & 0.5 & 1.25 & 2 \\
\hline
\end{tabular}

\section{Experimental Design Using Response Surface Methodology (RSM)}

The design of the experiment is the study of possible factor combinations in each of the independent experimental parameters, is a powerful tool for understanding complex processes for describing parameter interactions in multi-parameter systems. Particularly RSM is systematization of statistical and mathematical methods that are effective scrutiny for the modeling and analyzing the issues in engineering problems. ${ }^{19-23}$ The combined effects of time, temperature, phenol to alcohol feed mole ratio and catalyst to phenol ratio on the phenol conversion and selective yield of 2, 4-DTBP was studied in the present research as represented in the Scheme-2. ${ }^{16}$ These factors under various parameters combinations with a complex response have been studied.

\begin{tabular}{c|c|c|c|c|c|c}
\multicolumn{6}{c}{ Table-2: Experimental Design and Response Value } \\
\hline Run No. & $x_{1}$ & $x_{2}$ & $x_{3}$ & $x_{4}$ & $\begin{array}{c}\text { Conversion } \\
\text { of Phenol }\end{array}$ & $\begin{array}{c}\text { Selective Yield of } \\
\text { 2,4-DTBP }\end{array}$ \\
\hline 1 & -1 & -1 & 0 & 0 & 27.3 & 52.5 \\
\hline 2 & -1 & 0 & -1 & 0 & 19.6 & 57.3 \\
\hline 3 & -1 & 0 & 1 & 0 & 10.3 & 35.0 \\
\hline 4 & -1 & 0 & 0 & 1 & 26.8 & 57.8 \\
\hline 5 & -1 & 0 & 0 & -1 & 13.5 & 52.8 \\
\hline 6 & -1 & 1 & 0 & 0 & 35.6 & 41.3 \\
\hline 7 & 1 & -1 & 0 & 0 & 68.4 & 60.9 \\
\hline
\end{tabular}


RASĀYAN J. Chem.

Vol. 14 | No. 1 |261-269| January - March | 2021

\begin{tabular}{c|c|c|c|c|c|c}
\hline 8 & 1 & 0 & -1 & 0 & 55.3 & 59.0 \\
\hline 9 & 1 & 0 & 0 & 1 & 85.6 & 56.5 \\
\hline 10 & 1 & 0 & 0 & -1 & 59.3 & 56.2 \\
\hline 11 & 1 & 0 & 1 & 0 & 35.7 & 30.5 \\
\hline 12 & 1 & 1 & 0 & 0 & 89.6 & 32.4 \\
\hline 13 & 0 & -1 & -1 & 0 & 42.6 & 60.3 \\
\hline 14 & 0 & -1 & 0 & 1 & 71.4 & 51.9 \\
\hline 15 & 0 & -1 & 0 & -1 & 33.8 & 46.7 \\
\hline 16 & 0 & -1 & 1 & 0 & 19.5 & 27.8 \\
\hline 17 & 0 & 0 & -1 & -1 & 22.9 & 50.3 \\
\hline 18 & 0 & 0 & 1 & 1 & 24.6 & 58.0 \\
\hline 19 & 0 & 0 & 1 & -1 & 12.8 & 25.0 \\
\hline 20 & 0 & 0 & -1 & 1 & 68.4 & 32.0 \\
\hline 21 & 0 & 1 & -1 & 0 & 46.7 & 34.4 \\
\hline 22 & 0 & 1 & 0 & -1 & 48.3 & 32.2 \\
\hline 23 & 0 & 1 & 0 & 1 & 76.4 & 45.5 \\
\hline 24 & 0 & 1 & 1 & 0 & 26.7 & 26.4 \\
\hline 25 & 0 & 0 & 0 & 0 & 76.6 & 59.4 \\
\hline 26 & 0 & 0 & 0 & 0 & 77.2 & 59.3 \\
\hline 27 & 0 & 0 & 0 & 0 & 79.9 & 59.1 \\
\hline & & & &
\end{tabular}

The present study involves 4 factors such as time, temperature, phenol to alcohol feed mole ratio and catalyst to phenol ratio and 3 level design based on limitations of the experimental conditions for multi response. Phenol tert-butylation has been reported with immidazole based sulfonic acid functionalized ionic liquids ${ }^{16,17,24}$ from which the factor levels were chosen. For this problem, central composite design (CCD) by response surface methodology the experimental responses generate the second order model using Box-Behnken method. Box-Behnken method has the best precision because of spherical, revolving and linear trend-free design and systems with effective curvature in the response. The following equations are used calculating conversion and selective yield.

Conversion of phenol $=\frac{\left\{\begin{array}{c}\text { weight of phenol in } \\ \text { reactant mixture }\end{array}\right\}-\left\{\begin{array}{c}\text { weight of phenol in } \\ \text { product mixture }\end{array}\right\}}{\text { weight of phenol in reactant mixture }} * 100$ Selective yield of 2, 4-DTBP $=\frac{\left\{\begin{array}{c}\text { weight of 2, 4-DTBP in } \\ \text { product mixture }\end{array}\right\}}{\left\{\begin{array}{c}\text { weight of phenol converted } \\ \text { into alkylated product }\end{array}\right\}} * 100$

In order to describe the effects of reaction time $\left(x_{1}\right)$, Temperature $\left({ }^{x_{2}}\right)$, phenol to TBA mole ratio $\left({ }^{x_{3}}\right)$, and catalyst to phenol mole ratio $\left(x_{4}\right)$ on percentage phenol conversion and selective yield to 2,4-ditert-butyklated phenol $(2,4$-DTBP), The coded values of the process parameters were determined by the following equation:

$$
x_{i}=\frac{U_{i}-U_{0}}{\Delta U_{i}}
$$

Where $x_{i}$ is the independent variable coded value; $\mathrm{U}_{\mathrm{i}}$, is the independent variable real value; $\mathrm{U}_{0}$ is the independent variable real value on the center point; and $\Delta U_{i}$, step change value. The second-order polynomial equation for the relationship among the four variables and response is approximated through equation (2). ${ }^{25}$

$$
Y_{c}=a_{0}+\sum a_{i} x_{i}+\sum a_{i i} x_{i}^{2}+\sum a_{i j} x_{i} x_{j}
$$

Where $Y_{c}$ is the predicted response by the model; $x_{i}$ and $x_{j}$ are independent variables; $a_{0}$ is equation constant; $a_{i}, a_{i i}, a_{i j}$ are regression coefficients of the model. Table-1 shows the variables and their levels for the Box-Behnken design to this experimental study.

Box-Behnken design matrix was determined and experimental results of the variables with actual level given in Table-2, these design matrix values were explored by the relationship in Table- 1 . The adeptness and accuracy of the second-order-multiple regression models shall be estimated by the coefficient of determination $\left(\mathrm{R}^{2}\right)$. The coefficients such as ${ }^{a_{i}}$ and two interaction factors ${ }^{a_{i i}}$ and ${ }^{a_{i j}}$ have been predicted from the experimental results. The regression analysis of the experimental data and the 
responses were estimated using 'MINITAB' ${ }^{\mathrm{TM}}$ ' (Version 15) software. The expression of the multiple regression model fitwas analyzed by the coefficient of regression $\left(\mathrm{R}^{2}\right)$ and F-test and regression coefficient significance was tested by a Student's t-test. The confidence levels of the experimental values of reaction time, temperature, reactant mole ratio and catalyst loading are about $95 \% .{ }^{22}$

Table-3: Estimated Regression Coefficients and Corresponding Statistical t- and P- Values for Conversion of Phenol

\begin{tabular}{c|c|c|c}
\hline Term & Coefficient Factor & $\mathrm{t}$ & $\mathrm{P}$ \\
\hline Constant & 44.209 & -4.99 & 0.000 \\
\hline$x_{1}$ & 0.054 & 3.54 & 0.004 \\
\hline$x_{2}$ & 0.875 & 3.51 & 0.004 \\
\hline$x_{3}$ & 13.931 & 7.74 & 0.000 \\
\hline$x_{4}$ & 17.762 & 2.74 & 0.018 \\
\hline$x_{1}{ }^{2}$ & 0.000 & -6.92 & 0.000 \\
\hline$x_{2}{ }^{2}$ & 0.006 & -3.64 & 0.003 \\
\hline$x_{3}{ }^{2}$ & 2.258 & -14.77 & 0.000 \\
\hline$x_{4}{ }^{2}$ & 4.015 & -5.99 & 0.000 \\
\hline$x_{1}{ }^{*} x_{2}$ & 0.001 & 1.24 & 0.240 \\
\hline$x_{1}{ }^{*} x_{3}$ & 0.011 & -0.99 & 0.343 \\
\hline$x_{1}{ }^{*} x_{4}$ & 0.015 & 1.25 & 0.236 \\
\hline$x_{2}{ }^{*} x_{3}$ & 0.130 & 0.30 & 0.771 \\
\hline$x_{2}{ }^{*} x_{4}$ & 0.174 & -0.91 & 0.380 \\
\hline$x_{3}{ }^{*} x_{4}$ & 3.477 & 5.17 & 0.000 \\
\hline & & & \\
\hline
\end{tabular}

Table-4: Analysis of Variance Model Regression on Conversion of Phenol

\begin{tabular}{c|c|c|c|c|c|c}
\hline Source & DF & Seq SS & Adj SS & MS & F & P \\
\hline Regression & 14 & 15347.8 & 15347.8 & 1096.3 & 40.31 & 0.000 \\
\hline Linear & 4 & 8296.5 & 1779.4 & 444.9 & 16.36 & 0.000 \\
\hline Square & 4 & 6189.6 & 6189.6 & 1547.4 & 56.89 & 0.000 \\
\hline Interaction & 6 & 861.7 & 861.7 & 143.6 & 5.28 & 0.007 \\
\hline Residual error & 12 & 326.4 & 326.4 & 27.2 & & \\
\hline Lack-of-Fit & 10 & 324.8 & 324.8 & 32.5 & 42.05 & 0.023 \\
\hline Pure Error & 2 & 1.5 & 1.6 & 0.8 & & \\
\hline Total & 26 & 15674.2 & & & & \\
\hline
\end{tabular}

$\mathrm{R}^{2}=97.92 \%, \quad \mathrm{R}^{2}(\overline{\operatorname{adj}})=88.04 \%, \mathrm{~F}_{0.05}(9,5)=2.64$. DF-Degree of freedom; SS-sum of squares; MS-mean of squares; F-F-value; P- significance level of P-value (a significance level $<0.05$ ).

\section{RESULTS AND DISCUSSION}

The complex effect of process variables namely, reaction time, temperature, reactant mole ratio and catalyst to phenol mole ratio on the conversion of phenol and selective yield of 2, 4-DTBP was investigated using Box-Behnken design to visualize the effects of independent factors on responses. The Student ' $t$ '-test was used to determine the significance of the regression coefficients of the parameters. The significance of all the interactions among the variables is to analysis tool was used as P-values. In general, a low probability 'P' value in Fischer's ' $F$-test' values indicates the significance of the regression model. The coefficients with the larger the value of $t$ and smaller the value of $P$ is more significant for all the variables an interactions. Tables-3 and 5 list the regression coefficients, $t$ and $\mathrm{P}$ values for all the linear, quadratic and interaction effects of the parameters. The coefficients for the linear and quadratic effect of reaction time, temperature, reactant mole ratio and catalyst to phenol IONIC LIQUID CATALYZED Tert-BUTYLATION OF PHENOL 264 
RASĀYAN J. Chem.

Vol. 14 | No. 1 |261-269| January - March | 2021

mole ratio $(\mathrm{P}<0.05)$ were highly significant as shown the Tables-3 and 5. Comparatively less significant in linear and quadratic coefficients to the coefficients of interactive effects (least significant). The real response data plotted against the predicted responses presented in Table- 1 . The predicted responses in the points above or below the diagonal line mean areas of over or under the corresponding prediction. ${ }^{20,26}$ Figure-1 and 2 shows the plot of residuals plotted versus the predicted responses. The points should fall within a horizontal band centered at zero.

Table-5: Estimated Regression Coefficients and Corresponding Statistical t- and P- Values for Selectivity of 2, 4-DTBP

\begin{tabular}{c|c|c|c}
\hline Term & Coefficient Factor & $\mathrm{t}$ & $\mathrm{P}$ \\
\hline Constant & 26.406 & -2.23 & 0.046 \\
\hline$x_{1}$ & 0.032 & 2.90 & 0.013 \\
\hline$x_{2}$ & 0.523 & 5.41 & 0.000 \\
\hline$x_{3}$ & 8.321 & 2.37 & 0.036 \\
\hline$x_{4}$ & 10.609 & 1.46 & 0.170 \\
\hline$x_{1}{ }^{2}$ & 0.000 & -0.53 & 0.609 \\
\hline$x_{2}{ }^{2}$ & 0.003 & -7.92 & 0.000 \\
\hline$x_{3}{ }^{2}$ & 1.349 & -9.43 & 0.000 \\
\hline$x_{4}{ }^{2}$ & 2.398 & -3.06 & 0.010 \\
\hline$x_{1}{ }^{*} x_{2}$ & 0.000 & -2.76 & 0.017 \\
\hline$x_{1}{ }^{*} x_{3}$ & 0.007 & -1.01 & 0.332 \\
\hline$x_{1}{ }^{*} x_{4}$ & 0.009 & -0.75 & 0.465 \\
\hline$x_{2}{ }^{*} x_{3}$ & 0.078 & 3.92 & 0.002 \\
\hline$x_{2}{ }^{*} x_{4}$ & 0.104 & 1.28 & 0.223 \\
\hline$x_{3}{ }^{*} x_{4}$ & 2.077 & -0.13 & 0.900 \\
\hline & & &
\end{tabular}

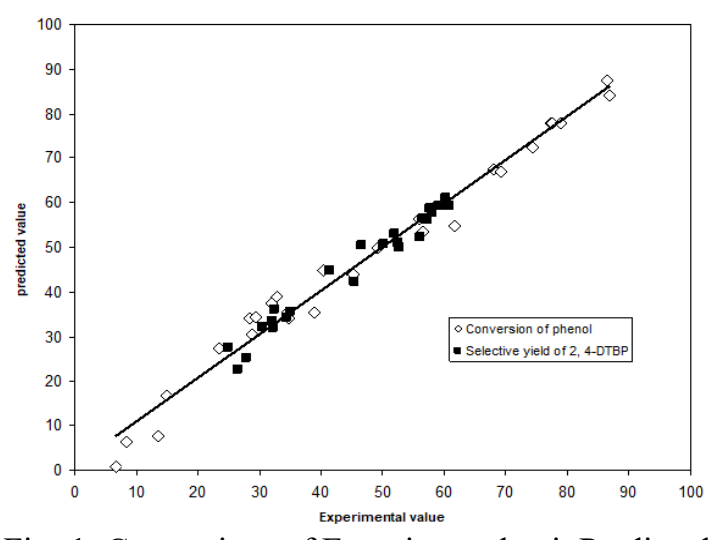

Fig.-1: Comparison of Experimental wit Predicted Values of Phenol Conversion and Selective Yield of 2, 4-DTBP.

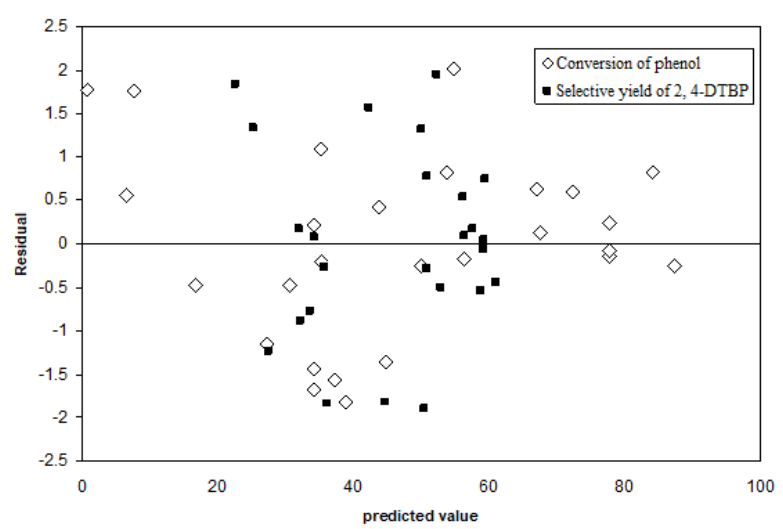

Fig.-2: Comparison of Experimental with Predicted Values of Phenol Conversion and Selective Yield of 2, 4-DTBP.

Table-6: Analysis of Variance Model Regression on Selective Yield of 2, 4-DTBP

\begin{tabular}{c|c|c|c|c|c|c}
\hline Source & DF & Seq SS & Adj SS & MS & F & P \\
\hline Regression & 14 & 4005.0 & 4005.0 & 286.1 & 29.48 & 0.000 \\
\hline Linear & 4 & 2465.9 & 314.3 & 78.6 & 8.10 & 0.002 \\
\hline Square & 4 & 1284.7 & 1284.7 & 321.2 & 33.10 & 0.000 \\
\hline Interaction & 6 & 254.4 & 254.4 & 42.4 & 4.37 & 0.014 \\
\hline
\end{tabular}


RASĀYAN J. Chem.

Vol. 14 | No. 1 |261-269| January - March | 2021

\begin{tabular}{c|c|c|c|c|c|c}
\hline Residual error & 12 & 116.4 & 116.4 & 9.7 & & \\
\hline Lack-of-Fit & 10 & 116.4 & 116.4 & 11.6 & 498.84 & 0.002 \\
\hline Pure Error & 2 & 0.1 & 0.1 & 0.0 & & \\
\hline Total & 26 & 4121.4 & & & & \\
\hline
\end{tabular}

$\mathrm{R}^{2}=97.17 \%, \quad \mathrm{R}^{2}(\mathrm{adj})=83.73 \%, \mathrm{~F}_{0.05}(9,5)=2.64$. DF-Degree of freedom; SS-sum of squares; MS-mean of squares; F-F-value; P- significance level of P-value (a significance level $<0.05$ ).
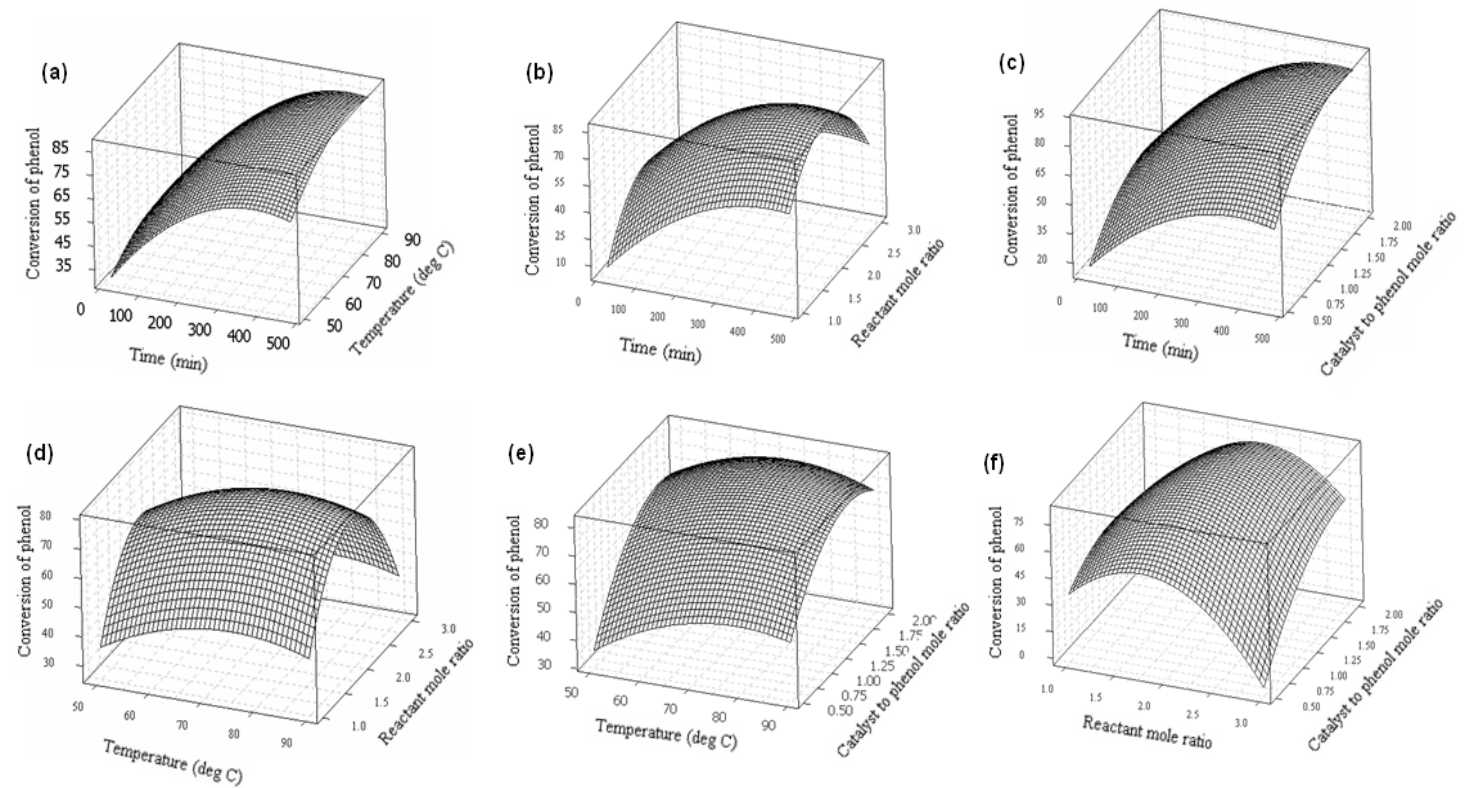

Fig.-3: Response Surface Plot showing the Predicted Values of Phenol Conversion: Effect of Time and Catalyst to Phenol Mole Ratio (a) Time and Reactant Mole Ratio (b) Time and Temperature (c) Reactant Mole Ratio and Catalyst to Phenol Mole Ratio (d) Temperature and Catalyst to Phenol Mole Ratio (e) Temperature and Reactant Mole Ratio (f) on Phenol Conversion. Other Variables are held at Constant Level.
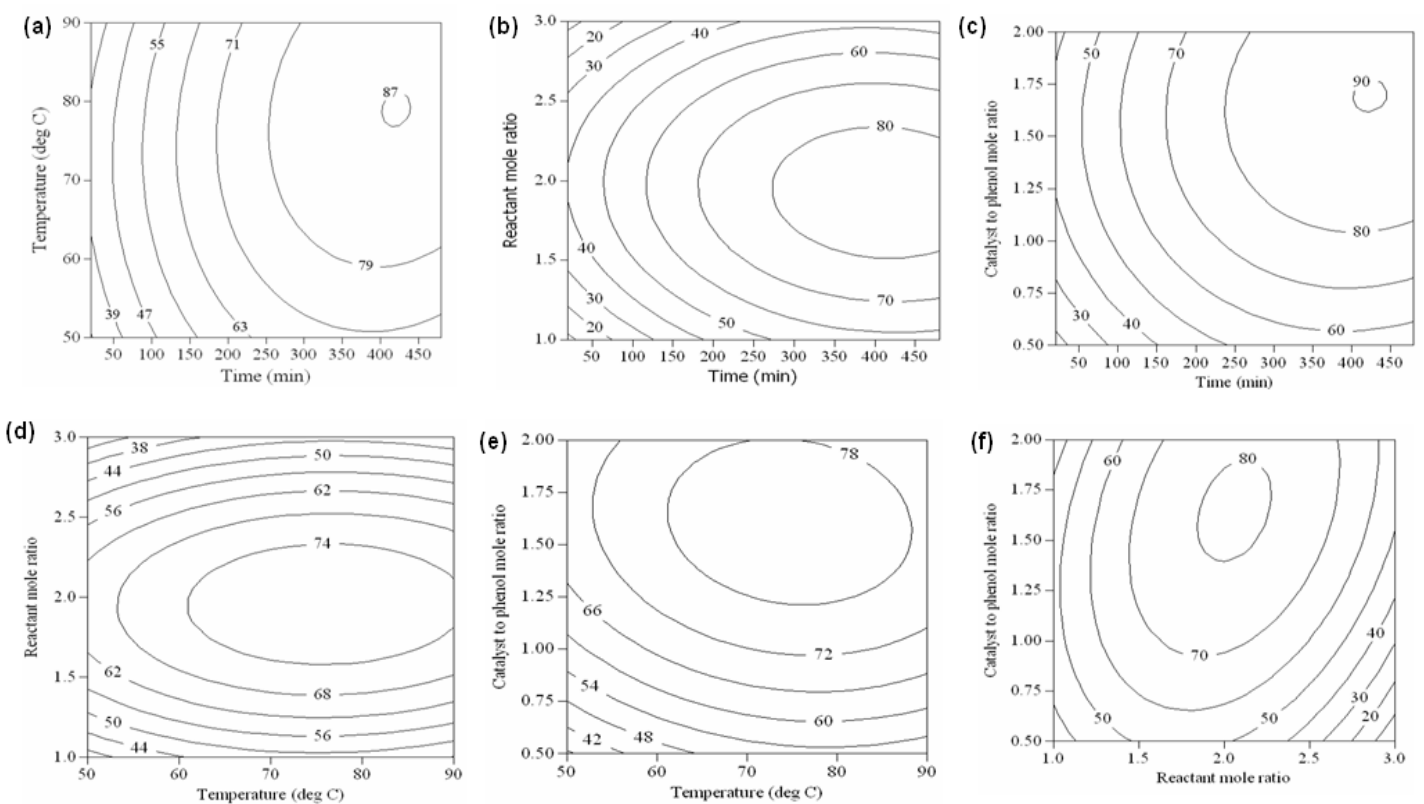

Fig.-4: Contour Plot Showing the Predicted Phenol Conversion: Effect of Time and Catalyst to Phenol Mole Ratio (a) Time and Reactant Mole Ratio (b) Time and Temperature (c) Reactant Mole Ratio and Catalyst to Phenol Mole Ratio (d) Temperature and Catalyst to Phenol Mole Ratio (e) Temperature and Reactant Mole Ratio (f) On Phenol Conversion. Other Variables are held at Constant Level.

The studentized residual size should be independent of its predictive value, it implies that the distribution should be about the same across all levels of the predicted values. The analysis of variance (ANOVA) table was used to test the statistical significance of the ratio of mean square due to 
RASĀYAN J. Chem.

Vol. 14 | No. 1 |261-269| January - March | 2021

regression and mean square due to residual error. The results, in the form of analysis of variance (ANOVA), are given in Tables-4 and 6. From these tables, it is evident that the F-statistical values of linear and squared regression were of higher significance. Generally, P-values lower than 0.05 indicate that the model is considered to be statistically significant at the $95 \%$ confidence level. The variation in the response should be clarified by the large value of $\mathrm{F}$ indicates by the regression model equation, it was observed in the F-test values for all regressions were higher as shown in the tables. ${ }^{20,27}$
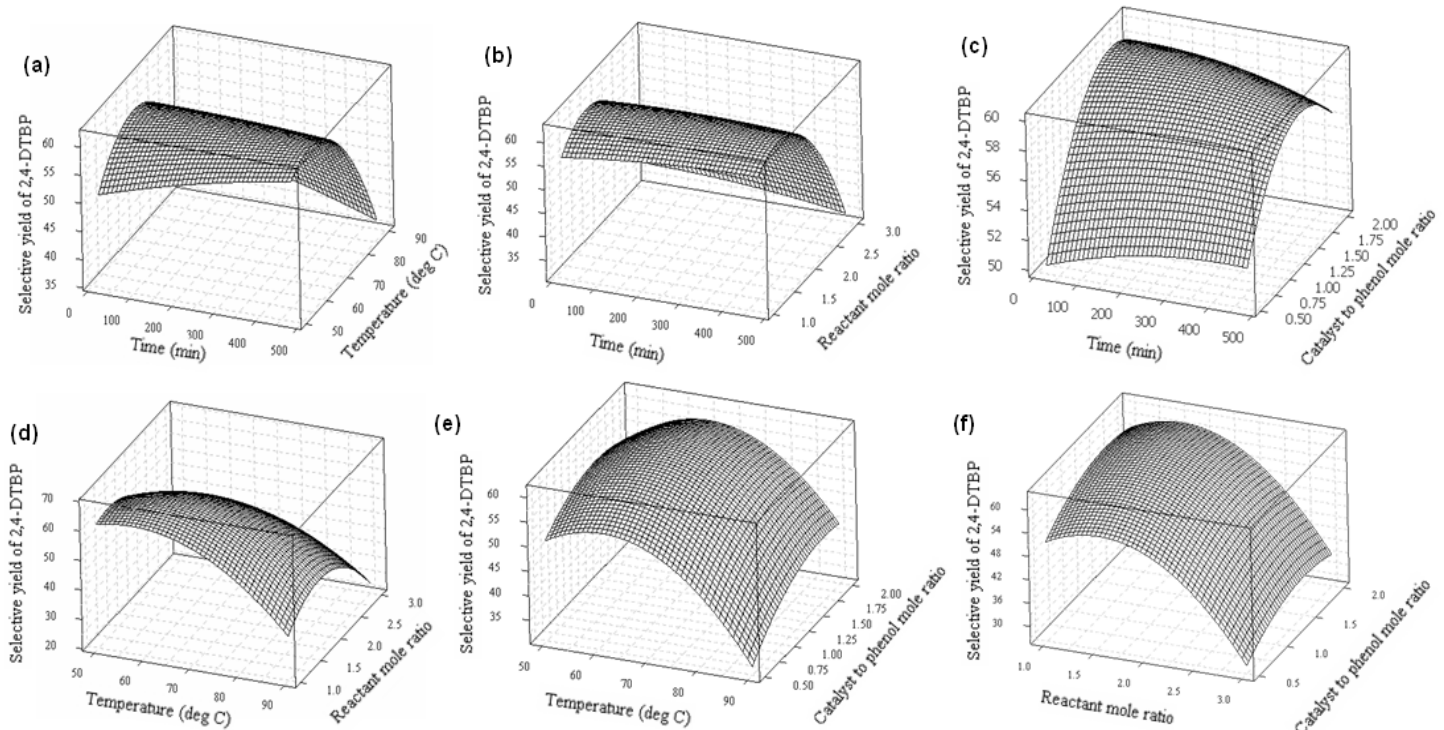

Fig.-5: Response Surface Plot showing the Predicted Selective Yield of 2, 4-tert-di-butylphenol (2, 4-DTBP): Effect of Time and Temperature (a) Time and Reactant Mole Ratio (b) Time and Catalyst Phenol Mole Ratio

(c)Temperature and Reactant Mole Ratio (d) Temperature and Catalyst to Phenol Mole Ratio (e) Reactant Mole Ratio and Catalyst to Phenol Mole Ratio (f) on Selective Yield of 2, 4-DTBP. Other Variables are held at Constant Level.

The second-order polynomial equation is highly significant and acceptable following the F-test value of phenol conversion and selective yield of 2, 4-DTBP is greater than tabulated F0.05 $(9,5)$-test (2.64), which indicates that the actual relationship between the response and the variables highly significant. Predicted values of phenol conversion and selective yield of 2, 4-DTBP are presented in Figs.-3 to 6 .
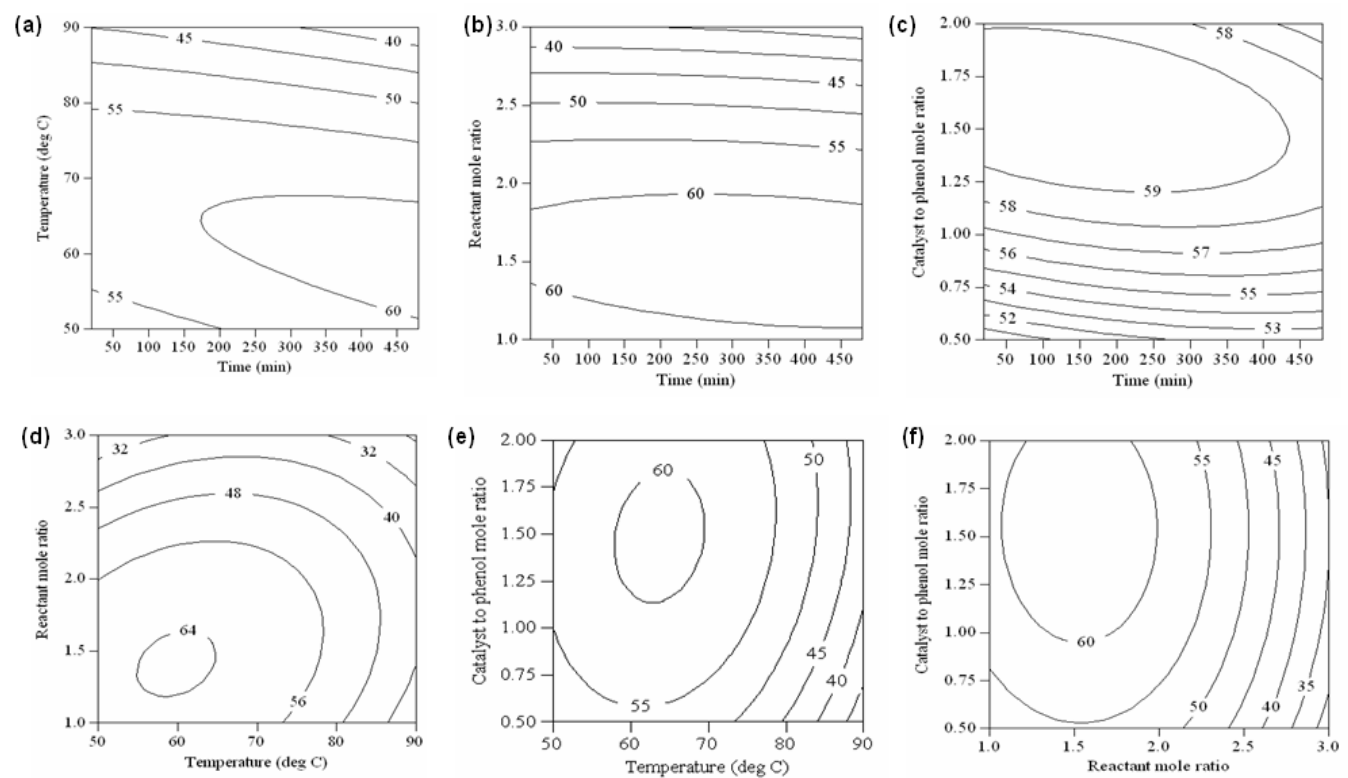

Fig.-6: Contour Plot showing the Predicted Selective Yield of 2, 4-tert-di-butylphenol (2, 4-DTBP): Effect of

Time and Temperature (a) Time and Reactant Mole Ratio (b) Time and Catalyst Phenol Mole Ratio(c)

Temperature and Reactant Mole Ratio (d) Temperature and Catalyst to Phenol Mole Ratio (e) Reactant Mole Ratio and Catalyst to Phenol Mole Ratio (f) on Selective Yield of 2, 4-DTBP. Other Variables are holding at Constant Level. 
Predicted values match with the experimental data points, indicating a good fitness (R2 value of 0.98 for conversion of phenol and R2 value of 0.97 for a selective yield of 2, 4-DTBP). The three dimensional response plots and contour plots obtained from the predicted models are presented in Fig.-3, 5 and Fig.-4, 6 respectively. The response surfaces of mutual interactions among the variables were found to be elliptical. The response surface and contour plots are given in Fig.-3 to 6 show the relative effects of any two variables when the other variables are kept constant.

\section{CONCLUSION}

Tert-butylation of phenol with tert-butyl alcohol in a batch reactor was performed at the liquid phase to optimize process parameters such as reaction time, temperature, reactant mole ratio and catalyst (ionic liquid) to phenol mole ratio on the conversion of phenol and selective yield of 2, 4-DTBP. The optimizations study for the linear, square and interactive effects of independent for the process parameters. A fractional factorial design and central composite design of Box-Behnken method were implemented to determine the second-order model relating to the tert-butylation of phenol. F-test and $\mathrm{P}$-values show the parameters have highly significant and influenced on the phenol conversion and selective yield of 2, 4-DTBP. The optimum parameters for the tert-buylation of phenol with TBA using ionic liquid catalyst were found at the temperature of $77^{\circ} \mathrm{C}$, phenol to alcohol ratio of $1: 2$, catalyst (IL) to phenol ratio of 1: 1.7 and 433 minutes reaction time. These optimum parameters gives a maximum of $91.4 \%$ conversion of phenol corresponding to the parameter maximum of $50.5 \%$ selective yield of 2, 4-DTBP. Maximum Selectivity $66.5 \%$ observed with optimized parameters of reaction time 480 minutes, the temperature of $55^{\circ} \mathrm{C}$, phenol to alcohol ratio of 1:1.3 and catalyst (IL) to phenol ratio of 1: 1.3 with $61.2 \%$ conversion of phenol. The phenol conversion and selectivity was validated experimental results with calculated value, the conversion and selectivity to 2, 4-DTBP similar to calculated value.

\section{REFERENCES}

1. G.A. Olah, V.P. Reddy, G.K.S. Prakash, Kirk-Othmer Encyclopedia of Chemical Technology, John Wiley \& Sons, Inc (2000), DOI:10.1002/0471238961.0618090515120108.a01

2. J. Pospisil, Polymer Degradation and Stability, 20, 181(1988),DOI:10.1016/01413910(88)90069-9

3. J. Murphy, Additives for Plastics Handbook, Second edi., Elsevier Science, Amsterdam, (2001), DOI:10.1016/B978-1-85617-370-4.50034-8

4. A. B. Shinde, N. S. Shrigadi and S. D. Samant, Applied Catalysis A: General, 276 , 5(2004), DOI:10.1016/S0926-860X(03)00612-4

5. E. Dumitriu and V. Hulea, Journal of Catalysis, 218 (2), 249 (2003), DOI:10.1016/S00219517(03)00159-3

6. P. Selvam, N. V. Krishna, A Sakthivel, Advanced Porous Materials, 1 (3), 239(2013), DOI:10.1166/apm.2013.1028

7. B. Chakraborty, Rasayan Journal of Chemistry, 12(4), 2183(2019), DOI:10.31788/RJC.2019.1245480

8. T. Jiang, Y. Xie, L. Dai, Y. Li and Q. Zhao, Reaction Kinetics Mechanisms and Catalysis., 125, 351(2018), DOI:10.1007/s11144-018-1394-0

9. T. Jiang, M. Fang, Y. Li, Q. Zhao and L. Dai, Journal of the Taiwan Institute of Chemical Engineers, 80, 1031(2017), DOI:10.1016/j.jtice.2017.09.029

10. X. Nie, X. Liu, C. Song and X. Guo, Journal of Molecular Catalysis A: Chemical, 332, 145(2010), DOI:10.1016/j.molcata.2010.09.010

11. T. Welton, Biophysical Reviews, 10, 691(2018), DOI:10.1007/s12551-018-0419-2

12. K. Ghandi, Green and Sustainable Chemistry, 4, 44(2014), DOI:10.4236/gsc.2014.41008

13. R. Ratti, Advances in Chemistry, 729842, (2014), DOI:10.1155/2014/729842

14. P. Elavarasan, S. Rengadurai and S. Upadhyayula, Chemical Engineering Journal Advances, 4, 100045 (2020), DOI:10.1016/j.ceja.2020.100045

15. N. V. Plechkova and K. R. Seddon, Chemical Society Reviews, 37, 123(2008), DOI: $10.1039 / \mathrm{b} 006677 \mathrm{j}$

16. P. Elavarasan, K. Kondamudi and S. Upadhyayula,. Chemical Engineering Journal, 166, 340(2011), DOI:10.1016/j.cej.2010.11.001

17. K. Kondamudi, P. Elavarasan, P.J. Dyson and S. Upadhyayula, Journal of Molecular Catalysis A: Chemical, 321, 34(2010), DOI:10.1016/j.molcata.2010.01.016 
RASĀYAN J. Chem.

Vol. 14 | No. 1 |261-269| January - March | 2021

18. P Elavarasan, K Kondamudi and S Upadhyayula, Journal Chemical Engineering and Process Technology, 73551116, (2016), DOI:10.4172/2157-7048.1000270

19. K. Hinkelmann and J. Jo, Journal of Statistical Planning and Inference, 72, 347(1998), DOI:10.1016/S0378-3758(98)00042-1

20. P Elavarasan, K Kondamudi and S Upadhyayula, Chemical Engineering Journal, 155, 355(2010), DOI:10.1016/j.cej.2009.07.019

21. S. Subhagar, S. Ramesh, P. Elavarasan and M. G. Devanesan, International Journal for Innovative Research in Multidisciplinary Field, DOI:10.2015/IJIRMF.2455.0620/IBCFT.03.2020

22. S.Rengadurai, B.Preetha and T.Viruthagiri, International Journal of ChemTech Research, 4, 21(2012)

23. Z. Masyithah, S.R. Yudhika, L. Simanjuntak and A. Ginting, Rasayan Journal of Chemistry, 12(2), 733 (2019), DOI:10.31788/RJC.2019.1225116

24. J. Gui, H. Ban, X. Cong, X. Zhang, Z. Hu and Z. Sun, Journal of Molecular Catalysis A: Chemical, 225, 27(2005), DOI:10.1016/j.molcata.2004.08.026

25. D.C. Motogomery, Design and Analysis of Experiments. 5th ed., John Wiley and Sons, New York (2004).

26. K. M. Lee and D. F. Gilmore, Applied Biochemistry and Biotechnology, 135, 101(2006), DOI:10.1385/ABAB:135:2:101

27. J. Segurola, N. S. Allen, M. Edge and A. M. Mahon, Progress in Organic Coatings, 37, 23(1999), DOI:10.1016/S0300-9440(99)00052-1

[RJC-6120/2020] 